\title{
Relação entre as dificuldades e a percepção que os estudantes do ensino médio possuem sobre a função das representações visuais no ensino de Química
}

\section{The relationship between the difficulties and the perception that high school students have about the role of visual representations in the teaching of Chemistry}

iD Fernando César Silva

Edyth Priscilla Campos Silva

Diogo Moreira Duarte

Franciele de Sousa Dias

\begin{abstract}
Universidade Federal de Minas Gerais (UFMG), Belo Horizonte, MG, Brasil.
\end{abstract}
Autor correspondente: fcsquimico@ufmg.br

Resumo: Neste artigo buscamos analisar a relação entre as dificuldades dos estudantes do Ensino Médio de escolas de Belo Horizonte (MG) e suas percepções sobre a função das representações visuais no Ensino de Química. Nesse sentido, os dados foram gerados a partir das atividades realizadas pelos estudantes, sendo essas orientadas por um estudo internacional realizado sobre o tema. Os resultados, analisados sob uma abordagem qualitativa, apontaram dificuldades de compreensão, construção e relação das representações visuais com os modelos, levando os estudantes a perceberem essas representações como necessárias apenas para uma ilustração da Química. Essa percepção implica no uso dessas representações como um produto que transmite seu conteúdo por si próprio, relacionando com as dificuldades identificadas. Como implicação desse estudo, sugerimos que as dificuldades possam ser minimizadas a partir de uma percepção dessas representações visuais como necessárias para apoiar hipóteses, produzir justificativas, fundamentar os argumentos, elaborar as explicações e expressar conclusões.

Palavras-chave: Educação básica; Ensino de química; Ensino médio; Representação visual; Processos de ensino e aprendizagem.

Abstract: In this article, we seek to analyze the relationship between the difficulties of high school students in schools in Belo Horizonte (MG, Brazil) and their perceptions of the role of visual representations in Chemistry Teaching. Thus, the data were generated from the activities carried out by the students, guided by an international study about the topic. The results indicated difficulties in the understanding, construction and relationship of visual representations with the models, and the fact that students do not perceive these representations as necessary only for the illustration of Chemistry. This perception by students implies the use of these representations, as a product that transmits its content by itself, relating it to identified difficulties. We suggest - as an implication of this study - that these difficulties can be minimized if visual representations can be perceived as necessary to support hypotheses, produce justifications, substantiate arguments, elaborate on explanations and express conclusions.

Keywords: Basic education; Chemistry teaching; High school; Visual representation; Teaching and learning processes.

Recebido em: 22/06/2020

Aprovado em: 23/07/2021 


\section{Introdução}

A compreensão das representações visuais tem sido considerada essencial para o sucesso dos estudantes nas aulas de Química, seja na escola ou na universidade (BEEK; LOUTERS, 1991; TASKIN; BERNHOLT, 2014). Esse sucesso também se estende para a vida profissional do químico, considerando que elas descrevem, parcialmente, as substâncias e suas propriedades e são usadas na produção do conhecimento (TASKIN; BERNHOLT, 2014). Jacob (2001) defende que, por um lado, os químicos projetam e sintetizam novos compostos no laboratório; por outro, fazem declarações analíticas e sintéticas sobre esses compostos em artigos de pesquisa. Dessa forma, a compreensão das representações visuais e as normas que regem o seu uso tornam-se essenciais para o entendimento da Química (JACOB, 2001).

No Ensino de Química, a natureza abstrata dessas representações e os aspectos teóricos com os quais elas se relacionam, têm sido indicados como algumas das explicações para as dificuldades dos estudantes (JOHNSTONE, 1993; TABER, 2009; TALANQUER, 2011; TASKIN; BERNHOLT, 2014; TERUYA et al., 2013). Aliado a isso, muitas vezes, elas são ensinadas por meio de abordagens baseadas na memorização, incluindo classificações e nomenclatura das substâncias que representam (FERREIRA; DEL PINO, 2009; MORTIMER, 1996; ROQUE; SILVA, 2008). Diversos pesquisadores (JOHNSTONE, 1993; QUADROS; SILVA; MORTIMER, 2018; TALANQUER, 2011; TREAGUST; CHITTLEBOROUGH, 2001) defendem que a abordagem dessas representações precisa ocorrer de forma conectada aos fenômenos, aos processos da química e aos aspectos teóricos necessários para a compreensão e interação com o mundo natural.

Na literatura, existem estudos diversos sobre as representações visuais envolvendo, por exemplo, a categorização das dificuldades dos estudantes para lidar com elas (TASKIN; BERNHOLT, 2014), a percepção que professores em formação inicial possuem sobre elas (FERREIRA; ARROIO; BUSTAMANTE, 2013; VLADUŠIĆ; BUCAT; OZIC, 2016), a sua relação com os gestos (GIORDAN; SILVA-NETO; AIZAWA, 2015), análises baseadas na teoria semiótica de Peirce (GOIS; GIORDAN, 2007; WARTHA; REZENDE, 2015), a sua função e estrutura em livros didáticos (HAN; ROTH, 2006) e a sua integração à prática científica (PERINI, 2004; PERINI, 2005a, 2005b; POZZER-ARDENGHI; ROTH, 2010).

Desses estudos, três em especial fundamentaram a construção desse artigo. Primeiramente, Taskin e Bernholt (2014), por categorizar as dificuldades dos estudantes ao lidar com as representações visuais, quanto à compreensão, construção e relação com os diagramas submicroscópicos. Os autores sugerem, também, a necessidade de uma compreensão mais ampla dessa temática, tanto na pesquisa quanto na prática educacional. Em segundo lugar, Talanquer (2011), por caracterizar as representações visuais, bem como os outros tipos de conhecimento químico. E finalmente, Perini (2004, 2005a, 2005b), por defender que as representações visuais são mais do que uma ilustração que expressa informações, mas são componentes dos argumentos usados na ciência.

Partindo desses estudos, buscamos contribuir com a área ao analisar a relação entre as dificuldades dos estudantes do Ensino Médio de escolas de Belo Horizonte (MG) e suas percepções sobre a função das representações visuais na Química. Esse 
objetivo nos leva a construir respostas para a seguinte questão de pesquisa: como as dificuldades dos estudantes ao lidar com as representações visuais se relacionam com a forma como a função dessas é percebida por eles nas aulas de Química?

\section{As representações visuais no ensino de química}

Taskin e Bernholt (2014), ao analisar estudos empíricos sobre as dificuldades dos estudantes para lidar com as representações visuais, perceberam que elas relacionam-se ao tipo de fórmulas químicas e as atividades operacionais exigidas desses estudantes. No que se refere aos tipos de fórmulas químicas, esses autores analisaram as dificuldades quanto às fórmulas moleculares e mínimas, estruturais e equações químicas. Esse recorte se sustenta para o que pretendemos, pois, na Educação Básica, essas são as principais representações com as quais os estudantes possuem contato. Em relação às atividades operacionais exigidas dos estudantes nos estudos analisados, esses autores categorizaram as dificuldades quanto à: (i) compreensão do significado e função; (ii) construção; (iii) interpretação; e (iv) relação com os diagramas submicroscópicos. Os autores justificaram essa categorização afirmando que as dificuldades são dependentes, ainda que seja considerado o mesmo tipo de fórmula da operação que a atividade proposta exige do estudante. Isso porque, segundo esses autores, os significados fundamentais, a nomenclatura e as outras regras, não fazem parte de uma teoria apenas, mas são convenções negociadas e estabelecidas ao longo dos anos pela comunidade de químicos.

A compreensão das fórmulas e equações químicas exige que os estudantes atribuam significado aos símbolos usados, reconhecendo a relevância e o papel de cada um deles. Para a construção das fórmulas mínimas e moleculares, há necessidade de se relacionar os nomes dos elementos e compostos, conectando os respectivos símbolos. Ao passo que, para a construção das fórmulas estruturais, a conectividade entre os símbolos que representam os átomos e o tipo de ligação entre eles deve ser reconhecida. Já a construção de uma equação química demanda reconhecer reagentes e produtos, a natureza da reação (reversível ou não), a estequiometria e a energia envolvida. A interpretação das fórmulas e equações químicas demanda dos estudantes a derivação de informações específicas (TASKIN; BERNHOLT, 2014), o que para nós já remete à compreensão. Por fim, na relação com os diagramas submicroscópicos, as fórmulas e as equações químicas devem ser vinculadas às partículas e processos no nível submicroscópico para a compreensão de suas diferentes funções. Além disso, para as equações químicas, essa relação mobiliza, também, o nível macroscópico, visto que as reações são dinâmicas e interdependentes entre reagentes e produtos (TASKIN; BERNHOLT, 2014).

Nesse sentido, as dificuldades dos estudantes não se encerram nas representações visuais, mas também ocorrem em decorrência das relações com os outros níveis, submicroscópico e macroscópico. A esse respeito, Alex $\mathrm{H}$. Johnstone, a partir de seus estudos, propôs três níveis necessários para a compreensão do conhecimento químico, quais sejam: (i) macroscópico, que representa o visível e o tangível; (ii) submicroscópico, que representa o molecular, o atômico e o invisível e, (iii) simbólico, que representa os símbolos e as equações (JOHNSTONE, 1993). Ainda que com algumas críticas (ARAÚJONETO, 2009; SOUZA, 2012), as ideias desse autor contribuem para a compreensão 
do conhecimento químico no contexto educacional, indicando a necessidade dos estudantes transitarem entre os três níveis.

Diversos autores ressignificaram essa proposta de Johnstone, dentre os quais, destaca-se Talanquer (2011), que, embora sua teoria apresente algumas limitações (SOUZA, 2012), ela também fornece mais elementos, de ordem didática, para o entendimento de algumas características da natureza do conhecimento químico. Para Talanquer (2011), esses níveis seriam mais bem caracterizados como tipos de conhecimento relevantes para o processo de ensino e aprendizagem em Química. Esse autor utiliza os seguintes termos para os níveis propostos por Johnstone (1993): (i) experiências que tratam do conhecimento ligado a tudo aquilo que percebemos, seja diretamente, por meio dos nossos sentidos (por exemplo, a combustão de um material) ou indiretamente, por meio do uso de equipamentos e instrumentos (o valor do pH de uma solução fornecida pelo pHmetro); (ii) modelos que se referem aos modos de prever, descrever e explicar os fenômenos químicos e (iii) visualizações que são o meio de representar alguns aspectos dos dois outros tipos de conhecimento propostos pelo autor (por exemplo, são os símbolos químicos e fórmulas, desenhos de partículas, equações matemáticas, gráficos, animações, simulações, modelos físicos, dentre outros).

Taskin e Bernholt (2014) afirmam que as ideias de Talanquer (2011) contribuem para a compreensão conceitual acerca dos tipos de conhecimento químico que, a nosso ver, ocorre quando ele exemplifica as diferenças entre eles na "Experiência: - gás natural queima na presença de ar e pode ser usado para aquecer as coisas" (TALANQUER, 2011, p. 188, tradução nossa). Esse é o 'tipo' de conhecimento obtido a partir da experiência que as pessoas desenvolvem por meio de suas interações com o mundo. No entanto, esse fenômeno é reinterpretado quimicamente, no que se refere às teorias sobre a composição e reatividade da matéria, conforme descrito a seguir.

\footnotetext{
Modelo: o gás natural é composto, principalmente por metano, uma substância composta que sofre uma reação de combustão com uma substância simples do ar, o oxigênio, produzindo duas novas substâncias compostas, dióxido de carbono e água, e liberando energia nas formas de calor e luz. (TALANQUER, 2011 , p. 188, grifo do autor, tradução nossa).
}

Os conceitos científicos utilizados para construir esse modelo teórico (substância composta, substância simples, reação de combustão, energia, calor, luz), embora 'macroscópico' na natureza, está longe de ser palpável e visível. O modelo real pode ser pensado tanto de forma descritiva como explicativa de um fenômeno da natureza. A transposição da experiência (fenômeno estudado) para o modelo requer a compreensão de muitos conceitos complexos e ideias desenvolvidas pelos químicos para explicarem as propriedades e o comportamento da matéria. Driver et al. (1994) apud Talanquer (2011, p. 189) afirmam que a experiência e o modelo são dois tipos de conhecimento distintos e a pesquisa educacional aponta que os estudantes precisam de suporte considerável para aprender a "traduzir" esses conhecimentos de um para o outro. Em outras palavras, o modelo não é o fenômeno em si, mas uma construção social para a compreensão e interação com esse fenômeno.

Ainda discutindo sobre os três "tipos de conhecimento", Talanquer (2011, p. 189, tradução nossa) aponta que a experiência e o modelo são representados frequentemente usando o seguinte conjunto de sinais visuais (uma equação química): 
"Visualização: $\mathrm{CH}_{4(\mathrm{~g})}+2 \mathrm{O}_{2(\mathrm{~g})} \rightarrow \mathrm{CO} 2(\mathrm{~g})+2 \mathrm{H}_{2} \mathrm{O}_{(\mathrm{g})}+$ Energia". Nessa representação, foram indicadas informações específicas sobre a composição e os estados da matéria das substâncias envolvidas. Assim, para que tenha sentido, sem recorrer a qualquer modelo submicroscópico, torna-se necessário, não só compreender o significado dos símbolos e suas relações, mas entender como os químicos quantificam as diferentes substâncias envolvidas na reação. No entanto, uma equação química pode ser manipulada sem se compreender, significativamente, os conceitos e pressupostos dos modelos de matéria subjacentes ao que está representado. Nesse sentido, pedagogicamente, torna-se necessária a distinção clara entre modelos e visualizações (TALANQUER, 2011).

Talanquer (2011) explica que, mesmo sendo comum nos referirmos às visualizações como modelos, há diferenças entre os modelos teóricos da matéria, desenvolvidos pelos químicos para descrever, explicar ou prever as propriedades dos sistemas químicos, e os diferentes sinais visuais criados para facilitar a interpretação e comunicação de conceitos e ideias. A maioria dos modelos teóricos utilizados em Química, e mesmo os modelos criados por nossos estudantes, são entidades multicomponentes e dependentes de uma variedade de hipóteses, difíceis de capturar por uma única visualização. Por exemplo, o desenho de um átomo com elétrons que se movem em órbitas em torno de um núcleo ou o diagrama de energia de um átomo mostrando uma sequência de estados quantizados, são visualizações de elementos centrais do modelo do átomo de Bohr, mas eles não são o modelo em si (TALANQUER, 2011).

Assim como Talanquer (2011), Gilbert e Justi (2016) também consideram o conceito de visualização diferente do conceito de modelo; entendem, portanto, como um campo subordinado à modelagem. A criação de modelos e sua comunicação para outras pessoas envolvem visualizações. Entretanto, de acordo com Gilbert e Justi (2016), o termo visualização é usado confusamente, sendo mais adequado o uso de representações externas (ou públicas), as quais são fornecidas por um dos cinco sentidos. Os modos de representação externa de relevância na Educação em Ciências são: gestual, concreta, visuais estáticos (imagens, diagramas, gráficos, equações matemáticas e químicas), visuais dinâmicos (drama, animação, simulação), oral e auditiva. A visualização (representação externa por meio dos modos visuais estáticos e dinâmicos) desempenha um papel central para as atividades de criação de modelos, a sua avaliação pela comunidade científica e a sua comunicação aos estudantes de Ciências de todas as idades.

Para explicar o uso do termo 'representações externas', Gilbert e Justi (2016) ressaltam que todos os modelos são criados na mente dos indivíduos (modelos mentais), e a tentativa de transmitir a informação incluída neste modelo para outra pessoa pode ser interpretada pelo uso de um ou mais sentidos. Isso porque, o modelo mental envolve a produção de uma representação da visualização do próprio. Assim, essa representação, quando disponibilizada a terceiros no domínio público e, portanto, capaz de ser interpretada por cada indivíduo nesse domínio, pode ser chamada de uma representação externa (GILBERT; JUSTI, 2016). Dessa forma, o termo 'visualização' não seria adequado para se referir a esse tipo de conhecimento proposto por Talanquer (2011), já que essas representações já foram legitimadas por uma comunidade científica, ou seja, já não são mais do indivíduo, mas públicas. Apoiamos nessas ideias 
como justificativa do uso do termo "representações visuais", para nos referirmos às fórmulas mínimas e moleculares, estruturais e equações químicas.

No entanto, Taskin e Bernholt (2014) ainda destacam que as ideias de Talanquer (2011) não avançam na discussão do papel dessas representações, considerando-as também como um sistema com regras e convenções próprias. Não pretendemos fazer uma discussão baseada na semiótica, mas nos referir ao uso das representações visuais como meio de produção do conhecimento. Sendo assim, apoiados nas ideias de Perini (2005a, 2005b), defendemos que elas também são componentes dos argumentos necessários para a defesa de ideias e das explicações construídas na Química.

Reconhecemos que o conceito de representações visuais adotado por Perini (2005a, 2005b) é mais abrangente, pois inclui gráficos, diagramas e imagens produzidas por diversas técnicas, por exemplo, microscopia eletrônica e difração de raios-X (PERINI, 2005a). Dessa forma,

[...] as representações visuais são aquelas com algumas características espaciais que são interpretadas como significando algo sobre o referente. As características espaciais de uma figura podem se referir a relações espaciais (como no diagrama de uma molécula), relações temporais (linhas do tempo), relações entre propriedades (gráficos), etc. Outros recursos visíveis, como a cor, também podem contribuir para o significado das representações visuais, dependendo do sistema, mas o papel referencial das relações espaciais é a característica definidora das representações visuais. Por esse motivo, as formas visíveis de representações visuais estão relacionadas aos seus referentes. (PERINI, 2005b, p. 914, grifo nosso, tradução nossa).

Quando Perini (2005b) utiliza o exemplo do diagrama de uma molécula, ela se refere à fórmula estrutural da molécula, que permite indicar a disposição que os átomos se ligam uns aos outros, definindo as características estruturais do composto. Isso fica evidente a partir da discussão que Perini (2004) faz sobre a estrutura química da oestrona. Ela afirma que a posição das ligações representadas pelas linhas em direção aos símbolos, que exemplificam os átomos, é significativa. Por exemplo, na estrutura dada, os átomos de carbono são omitidos e se referem às linhas unidas em ângulo, e as outras extremidades dessas linhas se ligam a outros átomos. Dessa forma, a relação entre as posições desses átomos e as características estruturais do composto determina a identidade da molécula (PERINI, 2004).

Percebemos ainda que Perini (2005a, 2005b) considera as imagens que levaram à caracterização das moléculas como representações visuais. Por exemplo, uma fórmula estrutural pode ser proposta a partir das imagens (espectros) obtidas a partir de ressonância magnética nuclear e espectrometria de massas. Perini (2005a, 2005b) considera essas imagens como representações visuais, entretanto, Talanquer (2011) as considera como experiências que foram acessadas indiretamente por meio de equipamentos. Não buscamos classificar essas imagens (no caso, espectros) em experiências ou representações visuais, mas nos basear na perspectiva adotada por Perini $(2004,2005 a, 2005 b)$ para entendermos a função das representações visuais na construção do conhecimento químico.

Os cientistas defendem suas alegações de conhecimento por meio de diversos tipos de representações, tais como textos, equações matemáticas e imagens (como diagramas, gráficos, micrografias eletrônicas, etc.) (PERINI, 2002). Assim, as imagens são tratadas pelos cientistas como componentes de seus argumentos, cuja validade 
depende tanto das representações visuais quanto das representações linguísticas (PERINI, 2005a). De acordo com Perini (2005b), as representações visuais não são meras ilustrações, ou seja, não são expressões redundantes de informações já apresentadas por meio das representações linguísticas.

Perini (2002) defende que as representações visuais podem suportar a verdade ou a falsidade dos argumentos científicos, afirmando que elas são seus componentes genuínos. A autora exemplifica essa defesa por meio das avaliações dos artigos, pois as imagens que estão no artigo também são avaliadas pelos revisores. A relação entre essas imagens e a conclusão da avaliação indica se o argumento é convincente e coerente (PERINI, 2005b). A autora ainda afirma que, além das representações visuais comporem os argumentos, elas podem apoiar hipóteses e expressar conclusões, por exemplo: modelos de estruturas e mecanismos biológicos geralmente aparecem na forma de diagramas (PERINI, 2002). Não pretendemos discutir sobre a capacidade das representações visuais de sustentar a verdade ou a falsidade dos argumentos científicos, como a autora considerou, mas que tem sido criticada por Goodwin (2009). Entretanto, compartilhamos de suas ideias, quando ela afirma que as representações visuais são partes funcionais dos argumentos científicos. Nesse sentido, transpondo essas ideias para as aulas de Química, acreditamos que elas podem ressignificar o uso das representações visuais.

\section{Metodologia}

Esta pesquisa possui uma abordagem qualitativa, de natureza interventiva, na qual buscamos identificar as dificuldades e percepções dos estudantes do Ensino Médio sobre as representações visuais. É também uma pesquisa de aplicação (TEIXEIRA; MEGID-NETO, 2017), pois envolve planejamento e execução sobre a atividade desenvolvida na sala de aula, definida integralmente pelos pesquisadores. Além disso, conforme defendem esses autores, os objetivos não estão diretamente relacionados à transformação de uma realidade, mas na produção de conhecimento sistematizado sobre questões ligadas aos processos de ensino e aprendizagem.

Os dados foram coletados em três escolas da região metropolitana de Belo Horizonte, estado de Minas Gerais (MG), sendo duas da rede pública de ensino, uma federal e outra estadual, e uma da rede particular de ensino. A escolha dessas escolas se deu pelo fato de elas serem amplamente selecionadas pelos licenciandos com os quais um dos autores desse artigo trabalha, para realização dos estágios supervisionados. Os estudantes que participaram da coleta de dados receberam um Termo de Assentimento Livre e Esclarecido e um Termo de Consentimento Livre e Esclarecido que foi entregue a seus pais e responsáveis para assinatura. Os termos foram aprovados pelo Comitê de Ética da Pesquisa sob o número 84000418.5.0000.5149. Todos os estudantes, na época com idades entre 14 e 17 anos, tiveram seus nomes codificados para preservar suas identidades.

$\mathrm{Na}$ escola federal, a atividade foi aplicada em duas turmas totalizando 63 estudantes, sendo uma de segundo ano e outra de terceiro ano do Ensino Médio, integradas aos cursos técnicos de Análises Clínicas e Química, respectivamente. Nas escolas particular e estadual, a atividade foi aplicada em duas turmas de terceiro ano do Ensino Médio, totalizando 38 e 41 estudantes, respectivamente. No entanto, na escola particular foram analisadas as atividades de 31 estudantes, que se referem 
àqueles que devolveram os termos devidamente assinados. Optamos por aplicar para turmas finais do Ensino Médio, visto que os estudantes já teriam um contato maior com as representações visuais usadas nas aulas de Química.

A atividade realizada pelos estudantes foi construída a partir dos conteúdos indicados no Conteúdo Básico Comum de Química (CBC) (MINAS GERAIS, 2007). Além disso, algumas questões apresentadas no estudo de Taskin e Bernholt (2014) serviram como inspiração para a construção das questões aplicadas para os estudantes desse estudo, especialmente, quando envolvia as relações entre as fórmulas e equações químicas com os modelos (no caso, o modelo de Dalton).

No momento da aplicação da atividade, os alunos estavam estudando os conteúdos de Química Orgânica previstos no CBC (MINAS GERAIS, 2007). Dessa forma, as questões foram baseadas, principalmente, em fórmulas moleculares, estruturais e equações químicas envolvendo compostos orgânicos. Foram construídas 22 questões, que contemplavam: (i) a identificação e explicação das representações de elemento, átomo e substância nas fórmulas químicas, incluindo a explicação da ordem em que os átomos aparecem nessas fórmulas; (ii) representação de fórmulas moleculares, a partir do nome da substância; (iii) representação de fórmulas moleculares, usando aspectos do modelo de Dalton, incluindo características da substância representada nos três estados físicos; (iv) representação de fórmulas estruturais, a partir da fórmula molecular, bem como, a indicação de todos os símbolos constituintes, incluindo casos de isomeria; (v) leitura e construção de equações químicas, contemplando todos os símbolos convencionalizados para representar uma reação química; (vi) representação de equações químicas, usando aspectos do modelo de Dalton, inclusive usando reagente em excesso; (vii) utilidade das representações, sendo que em uma foi apresentada uma situação de produção de um fármaco, e os estudantes deveriam responder se as representações desempenham alguma função. Como havia questões diferentes, mas que contemplavam o mesmo objetivo, cada estudante respondeu no máximo oito. Optamos por esse número reduzido de questões para que os estudantes não se sentissem desmotivados ou cansados com a extensão da atividade. Antes de aplicar as questões para os estudantes das três escolas mencionadas, elas foram aplicadas para estudantes com o mesmo perfil de outra escola e discutidas em um evento (SILVA; SILVA, 2018). A partir da análise das respostas dos estudantes e das discussões realizadas com avaliadores e participantes do evento, algumas questões foram reformuladas para facilitar o entendimento do que era solicitado e evitar respostas que comprometesse a análise relatada nesse artigo.

A aplicação da atividade para os estudantes das três escolas ocorreu no primeiro semestre de 2019, com duração de aproximadamente 50 minutos, com a presença do professor da turma e pelo menos um dos autores desse artigo. Durante a realização da atividade, os estudantes não poderiam ser auxiliados pelo professor e nem consultar qualquer material. Optamos por usar questões integradas às atividades normais dos estudantes para evitarmos desconfortos ocasionados por ações que não estavam previstas.

As respostas dos estudantes para cada questão aplicada foi nossa unidade de análise, cuja justificativa se dá pelo fato de as representações visuais poderem ser 'capturadas' por meio de registros escritos (PERINI, 2005a, 2005b). Essas considerações se relacionam ao corpus da Análise Textual Discursiva (ATD), que se baseia em 
produções textuais. No entanto, essas produções textuais devem ser entendidas "[...] num sentido mais amplo, incluindo imagens e outras expressões linguísticas" (MORAES; GALIAZZI, 2016, p. 38).

Nesse sentido, as respostas dos estudantes foram analisadas por meio da ATD proposta por Moraes e Galiazzi (2016), que corresponde a uma metodologia de análise de dados de natureza qualitativa, valorizando tanto a descrição quanto a interpretação do fenômeno investigado, motivo pelo qual foi escolhida para a nossa análise. Os registros escritos produzidos pelos estudantes foram codificados e desmontados, "[...] fragmentando-os no sentido de produzir unidades constituintes, enunciados referentes aos fenômenos estudados" (MORAES; GALIAZZI, 2016, p. 33). Em seguida, relações foram estabelecidas para a categorização, que "[...] envolve construir relações entre as unidades [constituintes], combinando-as e classificando-as, [...] resultando daí sistemas de categorias" (MORAES; GALIAZZI, 2016, p. 34). Para a identificação das dificuldades dos estudantes, as categorias foram estabelecidas previamente a partir do estudo de Taskin e Bernholt (2014, p. 226, tradução nossa), conforme descrito no quadro 1. Essa forma de categorização é sistematizada e "[...] com grande direcionamento do pesquisador [...], numa sequência organizada de passos, [que] vai construindo e reconstruindo um sistema de categorias a partir das ideias" já estabelecidas.

Quadro 1 - Categorias usadas para a identificação das dificuldades dos estudantes sobre as representações visuais

\begin{tabular}{|c|c|c|}
\hline $\begin{array}{l}\text { Representações } \\
\text { Visuais }\end{array}$ & Categorias & Quando o estudante possui alguma dificuldade para ... \\
\hline \multirow{3}{*}{$\begin{array}{l}\text { Fórmula Molecular } \\
\text { e Mínima }\end{array}$} & Compreensão & $\begin{array}{l}\text { Explicar o significado, a relevância e a função dos símbolos químicos nas fórmulas e obter } \\
\text { as informações específicas a partir dessas fórmulas. }\end{array}$ \\
\hline & Construção & $\begin{array}{l}\text { Reconhecer que a ligação entre os símbolos e os nomes, segundo normas da International } \\
\text { Union of Pure and Applied Chemistry (IUPAC) - União Internacional de Química Pura e } \\
\text { Aplicada - são dados em função das fórmulas. }\end{array}$ \\
\hline & $\begin{array}{l}\text { Relação com os } \\
\text { modelos }\end{array}$ & $\begin{array}{l}\text { Compreender as diferentes funções dessas fórmulas químicas quando relacionadas às } \\
\text { partículas e aos processos em nível dos modelos. }\end{array}$ \\
\hline \multirow[b]{2}{*}{ Fórmula Estrutural } & Compreensão & O mesmo para as fórmulas mínimas e moleculares. \\
\hline & Construção & $\begin{array}{l}\text { Entender que não só a proporção de átomos deve ser considerada, mas também as } \\
\text { condições de ligação entre esses átomos, incluindo a possibilidade de ligações duplas } \\
\text { e triplas. }\end{array}$ \\
\hline \multirow{3}{*}{ Equações Químicas } & Compreensão & $\begin{array}{l}\text { Usar as equações para representar as reações, indicando uma série de detalhes descritivos } \\
\text { e conceituais. }\end{array}$ \\
\hline & Construção & $\begin{array}{l}\text { Escrever a(s) fórmula(s) mínima(s) e/ou molecular(es) do(s) reagente(s), avaliar e escrever } \\
\text { o(s) produto(s) formado(s), apresentar os estados físicos do(s) reagente(s) e produto(s), } \\
\text { escrever as condições que a reação ocorre (por exemplo, sob aquecimento, na presença de } \\
\text { luz etc) e equilibrar a equação, adicionando coeficientes adequados quando as fórmulas } \\
\text { químicas de reagentes e produtos já foram construídas. }\end{array}$ \\
\hline & $\begin{array}{l}\text { Relação com os } \\
\text { modelos }\end{array}$ & $\begin{array}{l}\text { Compreender as diferentes funções dessas equações químicas quando relacionadas às } \\
\text { partículas e aos processos a nível dos modelos. }\end{array}$ \\
\hline
\end{tabular}

Fonte: adaptado de Taskin e Bernholt (2014).

Taskin e Bernholt (2014) consideraram as fórmulas e equações químicas como categorias e propuseram quatro subcategorias: (i) compreensão do significado e função; (ii) configuração; (iii) interpretação; e (iv) relação com os diagramas submicroscópicos. As subcategorias foram nossas categorias e optamos por agregar as categorias (i) e (iii) por acreditarmos que elas se sobrepõem. Dessa forma, nossas categorias foram nomeadas como: (i) compreensão, (ii) construção e (iii) relação com os modelos (quadro 1). 
Para a compreensão de como os estudantes percebem a função das representações visuais na Química, não foram estabelecidas categorias previamente; elas emergiram dos nossos dados. Nesse modo de categorização, "[...] a partir de sua intensa impregnação com o [...] [corpus], o pesquisador vai percebendo diferentes categorias emergentes [...], uma a uma, sem uma preocupação inicial com um sistema de categorias em que estas se insiram" (TASKIN; BERNHOLT, 2014, p. 226, tradução nossa).

A partir das categorias e subcategorias resultantes desse processo de análise, tanto estabelecidas a priori quanto a posteriori, são construídos metatextos, que são “[...] constituídos de descrição e interpretação [...], um modo de teorização sobre os fenômenos investigados" (MORAES; GALIAZZI, 2016, p. 53-54), denominado de captação do novo emergente. A validade e confiabilidade dos metatextos se dá pelo rigor que a unitarização e categorização são feitas e pela argumentação envolvida na realidade empírica, trazendo, por meio de citações, exemplos de registros extraídos do corpus (MORAES; GALIAZZI, 2016). Nesse movimento de desconstrução e reconstrução, “[...] ainda que composto de elementos racionalizados e em certa medida planejados, em seu todo pode ser compreendido como um processo auto-organizado do qual emergem novas compreensões" (MORAES; GALIAZZI, 2016, p. 33-34).

A análise qualitativa realizada será apresentada neste texto a partir da descrição das dificuldades dos estudantes, dialogando com as dificuldades já identificadas por Taskin e Bernholt (2014). Em seguida, será apresentada a percepção dos estudantes sobre a função das representações visuais, interpretadas a partir das ideias de Perini (2005a, 2005b), o que permitiu estabelecer relações com as dificuldades identificadas.

\section{Resultados e discussão}

\section{Identificando a dificuldade dos estudantes}

Com o objetivo de identificar as dificuldades dos estudantes, analisamos as suas respostas considerando: (i) fórmulas mínimas e moleculares, no que se refere à compreensão, construção e relações com os modelos; (ii) fórmulas estruturais, no que se refere à compreensão e construção e, (iii) equações químicas, no que se refere à compreensão, construção e relações com os modelos, conforme indicado no quadro 1. Trouxemos também as dificuldades identificadas por Taskin e Bernholt (2014) para dialogar com os nossos resultados.

\section{Fórmulas mínimas e moleculares}

\section{Compreensão}

A compreensão das fórmulas mínimas e moleculares pelos estudantes exige que eles expliquem o significado e reconheçam a função dos símbolos químicos nessas fórmulas (TASKIN; BERNHOLT, 2014), conforme indicado no quadro 1. Nossos dados indicaram que alguns estudantes, quando questionados sobre a representação de uma substância, não reconheceram, por exemplo, $\mathrm{Mg}(\mathrm{s})$ como a substância magnésio. Se os estudantes já possuem dificuldades para identificar os símbolos químicos que representam o átomo, o elemento e a substância, a associação de símbolos que indicavam o estado físico, por exemplo, tornou essa identificação ainda mais difícil. 
Até mesmo a ordem desses símbolos, nas fórmulas, gerou confusão para os estudantes, quando perguntados, por exemplo, se as fórmulas moleculares como $\mathrm{CH}_{2} \mathrm{O}$ e $\mathrm{H}_{2} \mathrm{OC}$ representam a mesma substância. Um estudante afirmou que "as representações não indicam a mesma substância porque os átomos estão em posições diferentes. Na primeira, os hidrogênios estão ligados ao carbono e oxigênio; na segunda, apenas no oxigênio." Percebemos a dificuldade de compreender que a ordem dos símbolos na fórmula molecular não determina o tipo de substância.

Taskin e Bernholt (2014) elencaram, a partir de estudos empíricos, dificuldades semelhantes a essas que foram descritas: (i) os estudantes assumiram um código para a posição dos símbolos na fórmula molecular, acreditando que a ordem dos elementos determinava o tipo de substância. Por exemplo, a fórmula molecular $\mathrm{CH}_{2} \mathrm{O}$ foi entendida como um carbono ligado à água e não o metanal (um aldeído); e, (ii) os estudantes consideraram ainda que as fórmulas moleculares SH e HS representavam substâncias diferentes, acreditando que os índices das fórmulas moleculares e mínimas não possuem qualquer significado, como em algumas respostas, nas quais assumiram que $\mathrm{SiO}_{2}$ é equivalente a $\mathrm{Si}_{2} \mathrm{O}_{4}$. Eles ainda atribuíram os índices ao elemento subsequente, ao invés do precedente, fornecendo outros significados para os índices, como número de ligações duplas, número de mol e entenderam que os índices para os compostos iônicos se dão da mesma forma que os moleculares. Por exemplo, no caso do $\mathrm{MgCl}_{2^{\prime}}$ entenderam que o composto possui apenas 1 átomo de magnésio e 2 átomos de cloro (TASKIN; BERNHOLT, 2014).

\section{Construção}

Para a construção das fórmulas mínimas e moleculares, os estudantes deveriam reconhecer que a ligação entre os símbolos e os nomes se dá por normas da IUPAC (TASKIN; BERNHOLT, 2014), conforme foi apresentado no quadro 1. A partir de nossos dados, percebemos que a construção de uma fórmula de determinado composto, a partir de seu nome, foi motivo de dúvida para diversos estudantes. Ao serem solicitados para construírem a fórmula do dimetilmercúrio, eles escreveram $2 \mathrm{Hg}$. Outro detalhe, que nos chamou a atenção, foi o desenho de fórmulas estruturais como se fossem moleculares. Um estudante escreveu a fórmula molecular do etanol como $\mathrm{H}_{3} \mathrm{C}-\mathrm{CH}_{2}-$ $\mathrm{OH}$, ao invés da fórmula $\mathrm{C}_{2} \mathrm{H}_{6} \mathrm{O}$. Esses dados nos indicaram a dificuldade dos estudantes para diferenciar a fórmula molecular da fórmula estrutural, principalmente, quando se tratava de compostos orgânicos. Parece-nos que os estudantes entenderam que as normas regentes para a construção das fórmulas dos compostos orgânicos são totalmente diferentes dos inorgânicos.

Dificuldades semelhantes foram indicadas por Taskin e Bernholt (2014), quando, por exemplo, os estudantes não usaram adequadamente os ânions e cátions na fórmula de um sal. Além disso, desconheceram o papel dos números de oxidação e o significado de prefixos (di-, tri- etc) no nome dos compostos. Muitos estudantes possuíram dificuldades sobre a ordem dos símbolos químicos nas fórmulas de um composto, definindo-as pela ordem alfabética ou pela abundância relativa dos elementos no composto. Ademais, não utilizaram adequadamente as cargas iônicas e os índices. Por exemplo, os estudantes utilizaram íons como $\mathrm{Cl}_{2}-$ ou $\mathrm{Na}^{2+}$ para formar os compostos, $\mathrm{CaCl}_{2}$ ou $\mathrm{Na}_{2} \mathrm{SO}_{4}$, respectivamente (TASKIN; BERNHOLT, 2014). 


\section{Relações com os modelos}

As relações entre as fórmulas mínimas e moleculares aos modelos estão associadas à compreensão das diferentes funções dessas fórmulas e aos processos que as compõem, implicando em enormes exigências sobre as habilidades de abstração dos estudantes (TASKIN; BERNHOLT, 2014), conforme indicado no quadro 1. Foi solicitado aos estudantes que representassem o metano no estado líquido $\mathrm{CH}_{4}(\mathrm{I})$. Para isso, eles deveriam reconhecer o modelo usado para explicar que, no estado líquido, as moléculas não estão próximas e nem tão organizadas quanto no estado sólido, que elas possuíam uma liberdade de movimento maior que aquelas do estado sólido e menor que no gasoso. No entanto, os estudantes desenharam esferas indicando apenas uma molécula, o que não representa a distância entre elas. Além disso, quando solicitados para representar cinco moléculas de fluormetano $\left(\mathrm{H}_{3} \mathrm{CF}\right)$ nos três estados físicos, desconsideravam as ligações que existem entre os átomos envolvidos nos estados líquido e gasoso. Eles entenderam que ocorre um distanciamento entre os átomos e não entre as moléculas. Como exemplo, apresentamos a figura 1.

Figura 1 - Representação dos estados físicos do fluormetano $\left(\mathrm{H}_{3} \mathrm{CF}\right)$ de acordo com um estudante

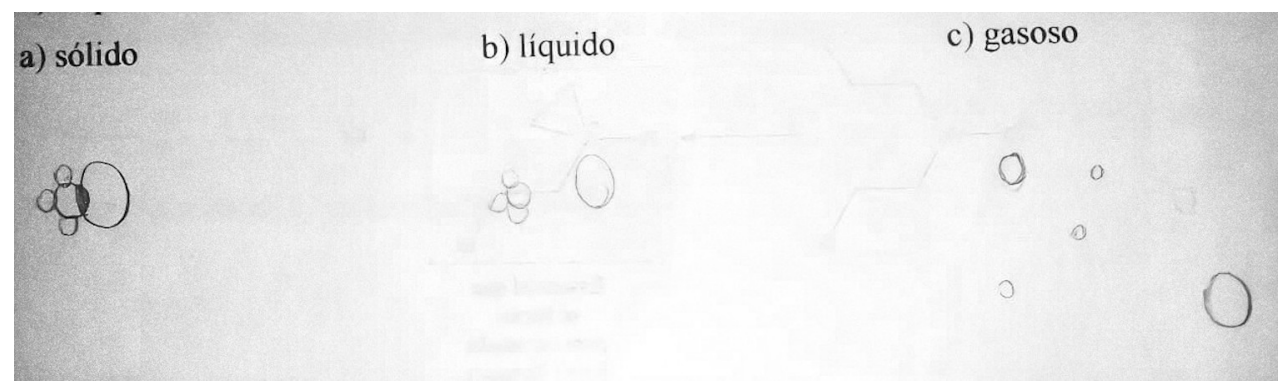

Fonte: foto de arquivo dos autores.

Percebemos que os estudantes possuíram dificuldade de relacionar o modelo que explica os estados físicos da substância com a fórmula molecular. Eles acreditaram que ocorre o rompimento da ligação entre os átomos ao invés da interação entre as moléculas. E ainda, desconsideraram que para representar os estados físicos de um composto há necessidade do uso de mais de uma espécie (moléculas, íons etc). A partir dos estudos empíricos categorizados por Taskin e Bernholt (2014), os estudantes, ao serem solicitados para representarem seis moléculas de amônia $\left(\mathrm{NH}_{3}\right)$, usando o modelo dos estados físicos, utilizaram agregados de círculos, do tipo $\mathrm{N}_{6} \mathrm{H}_{18}$ ou $\left(\mathrm{NH}_{3}\right)_{6}$, em vez de $6 \mathrm{NH}_{3}$. Além disso, não empregaram o modelo de ligação iônica para orientar a representação dos compostos iônicos, desconsiderando a rede iônica. Por exemplo, o cloreto de potássio $(\mathrm{KCl})$ sendo representado por um diagrama que indica um composto molecular e não uma rede iônica (TASKIN; BERNHOLT, 2014).

\section{Fórmulas estruturais}

\section{Compreensão}

Assim como para as fórmulas mínimas e moleculares, a compreensão de fórmulas estruturais está associada à explicação do significado, à relevância, à função dos símbolos químicos nas fórmulas e à obtenção de informações específicas a partir 
dessas fórmulas (TASKIN; BERNHOLT, 2014), conforme indicado no quadro 1. Em geral, os estudantes compreenderam as fórmulas estruturais apresentadas nas questões da atividade proposta, nas quais eles deveriam indicar em uma fórmula estrutural: pares de elétrons não ligantes, carga, tipo de ligações e átomos.

Nos estudos analisados por Taskin e Bernholt (2014), algumas dificuldades sobre a compreensão das fórmulas estruturais foram categorizadas: (i) explicitar todas as ligações entre os átomos em uma estrutura química, indicando que os estudantes possuem dificuldades em identificar substituintes vizinhos de um átomo de carbono, marcado nas fórmulas químicas, como, $\mathrm{CH}_{3}-\mathrm{CH}_{2}-\mathrm{Cl}$. Mesmo usando $\mathrm{H}_{3} \mathrm{C}-$ em vez de $\mathrm{CH}_{3}$ - para o grupo metila, que se destinavam a clarear a ligação entre os átomos na fórmula, as dificuldades ainda permanecem; (ii) extrair informações relevantes dos diferentes tipos de fórmulas estruturais. Muitos estudantes assumiram que uma ligação simples representava uma transferência de elétrons, ao passo que uma ligação dupla implica em uma partilha recíproca de elétrons; e, (iii) identificar diferenças entre as fórmulas estruturais de diferentes substâncias, principalmente quando são isômeros. Por exemplo, os estudantes reconheceram os isômeros apenas quando há mudança de grupo funcional, mas não identificaram os isômeros quando há somente a alteração de posição de um mesmo grupo.

\section{Construção}

A construção de fórmulas estruturais está associada à capacidade de os estudantes entenderem não só a proporção de átomos, que deve ser considerada, mas também as condições de ligação entre esses átomos, incluindo a possibilidade de ligações duplas e triplas (TASKIN; BERNHOLT, 2014), conforme indicado no quadro 1. Alguns estudantes escreveram a fórmula estrutural com um número inadequado de ligações para alguns átomos. Por exemplo, o átomo de carbono na posição central da fórmula ligado à ligação dupla com mais dois átomos de hidrogênio. Nesse processo de construção da fórmula estrutural, os estudantes tiveram dificuldade de reconhecer quantas ligações cada átomo pode fazer. Esse impasse é potencializado quando são solicitados a representar os isômeros, indicando ligações específicas entre os átomos para diferenciá-los.

Taskin e Bernholt (2014) também chegaram a esses resultados, afirmando que os estudantes desconhecem o número de ligações que determinado átomo pode fazer e a possibilidade de ligações duplas e triplas. Muitas estruturas são escritas faltando ligações, como compostos orgânicos com o octeto incompleto.

A localização de carga no átomo também é problemática, conforme indicado na figura 2. O estudante deveria escrever a fórmula estrutural a partir da fórmula condensada e indicar a carga no átomo, $\mathrm{H}_{3} \mathrm{CNH}_{3}{ }^{+}$.

Figura 2 - Fórmula estrutural do metilamônio representada por um estudante

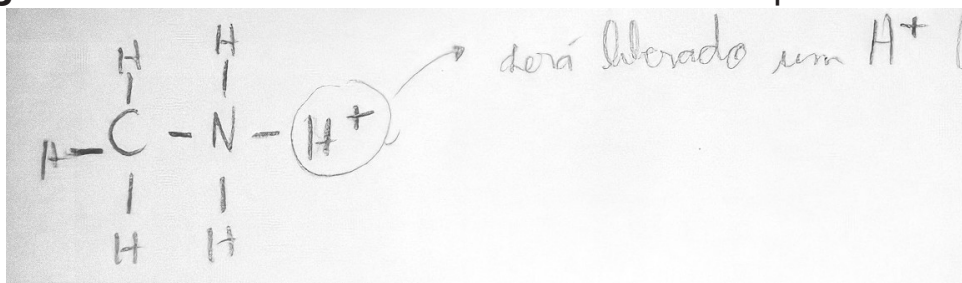

Fonte: foto de arquivo dos autores. 
Percebemos que, além de não indicar a carga no átomo correto, ele associou a carga ao átomo de hidrogênio, pois, segundo sua resposta, quando liberado como $\mathrm{H}^{+}$possui caráter ácido. $\mathrm{O}$ estudante considera que a carga pertence ao átomo de hidrogênio por ser liberado como $\mathrm{H}^{+}$. Reconhecer a posição da carga no átomo na fórmula estrutural foi uma das principais dificuldades dos estudantes.

Essa dificuldade também foi apontada por Taskin e Bernholt (2014), na qual os estudantes entenderam a construção de fórmulas estruturais de forma aditiva. Por exemplo, eles escreveram a fórmula estrutural do $\mathrm{SO}_{2}$ como $\mathrm{S}-\mathrm{O}-\mathrm{O}$. Isto indica que eles entenderam como se $\mathrm{O}_{2}$ fosse adicionado diretamente. Além disso, desconsideraram os conceitos de ligação química para distribuir os pares de elétrons não ligantes. Os estudantes não admitiram pares de elétrons não ligantes distribuídos em um átomo, acreditando que todos os pares de elétrons devam participar de uma ligação.

\section{Equações químicas}

\section{Compreensão}

A compreensão do significado e função das equações químicas está relacionada ao seu uso para representar as reações, indicando uma série de detalhes descritivos e conceituais, conforme indicado no quadro 1. Elas exibem não só a conversão de reagentes em produtos, mas também proporcionaram a base para os cálculos estequiométricos ou para construir mecanismos de reação. O uso de equações químicas é uma característica única da Química (TASKIN; BERNHOLT, 2014).

Muitos estudantes tiveram dificuldades de reconhecer os símbolos que constituem a equação, principalmente os estados físicos e o coeficiente estequiométrico, conforme indicado na transcrição, "Gás metano mais 2 moléculas de oxigênio [sic] para dióxido de carbono [sic] mais duas moléculas de água". Eles foram solicitados a escrever como seria a leitura da equação química, $\mathrm{CH}_{4(\mathrm{~g})}+2 \mathrm{O}_{2(\mathrm{~g})} \rightarrow \mathrm{CO}_{2(\mathrm{~g})}+2 \mathrm{H}_{2} \mathrm{O}_{(\mathrm{g})}+$ Energia. Muitos deles consideraram a molécula como sinônimo de quantidade de matéria, no que se refere ao coeficiente estequiométrico, ignoraram os estados físicos e o aspecto energético da reação. Ainda mais difícil, quando a energia envolvida na reação foi representada pelo símbolo $\Delta \mathrm{H}$, visto que alguns estudantes entenderam como variação de hidrogênio.

Taskin e Bernholt (2014) identificaram dificuldades semelhantes e outras relacionadas aos aspectos estequiométricos das equações químicas, tais como: (i) diferenciar entre o significado do sinal de adição em equações químicas e em operações matemáticas, isto é, o sinal de mais entre os reagentes é entendido como adicionado ou somado; (ii) interpretar o significado da seta em uma equação química, pois muitos associam com o sinal de igualdade das operações matemáticas; e, (iii) compreender a relação entre os coeficientes e índices, conforme alguns exemplos descritos a seguir. Muitos estudantes assumiram o mesmo significado para os coeficientes e índices. Por exemplo, para calcular a massa de $2 \mathrm{SO}_{2}$, seguiram o seguinte raciocínio: $2 \mathrm{~S}+\mathrm{O}_{2}=32 \mathrm{~g}$ $+32 \mathrm{~g}+16 \mathrm{~g}+16 \mathrm{~g}=96 \mathrm{~g}$ (ao invés de $128 \mathrm{~g}$ ). Eles também inverteram o significado de coeficientes e índices, escreveram fórmulas como $\mathrm{Cu}_{3}$ em vez de $3 \mathrm{Cu}$, por exemplo. Em uma fórmula como $5 \mathrm{Cu}\left(\mathrm{NO}_{3}\right)_{2}$ numa equação química, os estudantes assumiram que há 10 átomos de oxigênio, somando-se os índices dentro e fora dos parênteses com o coeficiente. Ademais, há estudantes que assumiram os coeficientes como necessários 
para equilibrar a camada de valência, para indicar a quantidade de prótons no último nível de energia ou para representar os números atômicos (TASKIN; BERNHOLT, 2014).

\section{Construção}

A construção de equações químicas pode abordar diferentes aspectos: (i) escrever a(s) fórmula(s) mínima(s) e/ou molecular(es) do(s) reagente(s); (ii) avaliar e escrever o(s) produto(s) formado(s); (iii) apresentar os estados físicos do(s) reagente(s) e produto(s); (iv) descrever as condições que a reação ocorre (por exemplo, sob aquecimento, na presença de luz etc); e (v) equilibrar a equação, adicionando coeficientes adequados quando as fórmulas químicas de reagentes e produtos já foram construídas (TASKIN; BERNHOLT, 2014), conforme indicado no quadro 1. Muitos estudantes, ao construírem uma equação química, tiveram dificuldades para reconhecer e representar a substância, o estado físico e o catalisador. Foi solicitado a eles que escrevessem a equação química que representa a reação entre os gases etino e hidrogênio com catalisador de platina para formar o gás etano. Um grande número deles escreveu a equação desconsiderando os estados físicos e o catalisador. Além disso, representaram o gás hidrogênio $\left(\mathrm{H}_{2}\right)$ como $4 \mathrm{H}$, conforme transcrito a seguir, " $\mathrm{C}_{2} \mathrm{H}_{2}+4 \mathrm{H} \rightarrow \mathrm{C}_{2} \mathrm{H}_{6}$ ".

Taskin e Bernholt (2014) também identificaram que os estudantes possuem dificuldades para balancear a equação química, alterando os índices dos compostos. E quando não o fizeram, também não explicaram o motivo de não poder fazê-lo. Os autores observaram que muitos deles não manipularam as fórmulas químicas em uma equação química. Além de alterarem os índices das fórmulas químicas, constroem as fórmulas dos compostos pela simples separação de fragmentos em conjunto, como por exemplo, a formação de $\mathrm{N}_{2} \mathrm{O}_{5}$ se dá pela junção de $\mathrm{N}_{2} \operatorname{com~} \mathrm{O}_{5}$.

\section{Relações com os modelos}

A relação entre equações químicas e os modelos se dá por meio da representação de partículas e os processos, de modo que os estudantes compreendam as suas funções, conforme indicado no quadro 1. Essa relação inclui também as experiências, compreendendo elementos dinâmicos e interdependências entre os reagentes e produtos (TASKIN; BERNHOLT, 2014). Como identificado também em outras categorias, os estudantes possuíam muitas dificuldades para representar os estados físicos das substâncias e a estequiometria da reação. Quando solicitados para representar a reação de combustão do metano, usando aspectos do modelo de Dalton, no momento em que os reagentes foram misturados e após algum tempo dessa mistura, os estudantes desenharam o que foi indicado na figura 3.

Figura 3 - Representação da equação $\mathrm{CH}_{4(g)}+2 \mathrm{O}_{2(\mathrm{~g})} \rightarrow \mathrm{CO}_{2(\mathrm{~g})}+2 \mathrm{H}_{2} \mathrm{O}_{(\mathrm{g})^{\prime}}$ usando aspectos do modelo de Dálton
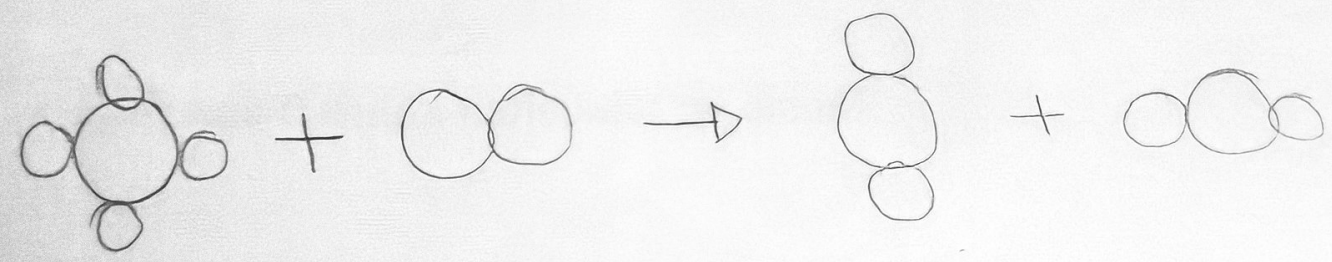

Fonte: foto de arquivo dos autores. 
Os estudantes não representaram a formação da outra molécula de água, desconsiderando a estequiometria da reação. Quando envolve reagente em excesso, o desafio ainda é maior para eles representarem. Ao serem solicitados para reproduzir uma equação química a partir de aspectos do modelo de Dalton, os estudantes acrescentaram o excesso do reagente na equação química representada. Essa dificuldade também foi identificada por Taskin e Bernholt (2014).

A representação das reações químicas por meio de equações químicas são fontes de diversas dificuldades, conforme elencadas por Taskin e Bernholt (2014): (i) considerar os reagentes como unidade nos diagramas que representam parcialmente os modelos; (ii) assumir que os coeficientes e índices são sinônimos. Além disso, negligenciar a conservação dos átomos. Esses autores perceberam que muitos estudantes desenharam, por meio de esferas, moléculas isoladas como entidades agrupadas, por exemplo, $2 \mathrm{H}_{2} \mathrm{O}$ como $\mathrm{H}_{4} \mathrm{O}_{2}$; (iii) desenhar diagramas envolvendo fórmulas mínimas e moleculares em uma equação química. Em um dos artigos analisados por eles, foi solicitado aos estudantes que desenhassem um diagrama para ilustrar a equação química $\mathrm{NiCl}_{2}+2 \mathrm{NaOH}_{(\text {aq) }} \rightarrow \mathrm{Ni}(\mathrm{OH})_{2(\mathrm{~s})}+2 \mathrm{NaCl}_{(\text {aq) }}$. No entanto, não desenharam os reagentes e produtos em solução aquosa na forma dissociada, indicando que não entenderam o significado dos símbolos para os estados da matéria. Ademais, alguns estudantes não consideraram o íon hidróxido ( $\mathrm{OH}$ ) como um íon poliatômico, desenhando diagramas em que os átomos de oxigênio e de hidrogênio do íon hidróxido ficaram separados. Outros interpretaram o íon cloreto $\left(\mathrm{Cl}^{-}\right)$como $\mathrm{Cl}_{2}$ no $\mathrm{NiCl}_{2}$ e o íon hidróxido como $(\mathrm{OH})_{2}$ em $\mathrm{Na}(\mathrm{OH})_{2}$. Eles associaram, também, os coeficientes na equação química com apenas o primeiro átomo da fórmula química. Por exemplo, $2 \mathrm{NaCl}$ representado por dois átomos de sódio ligados a um átomo de cloro ou de sódio diatômico separado do cloro. Além disso, alguns deles desenharam linhas que representam a ligação covalente para vincular os elementos $\mathrm{Na}$ e $\mathrm{Cl}$, criando assim uma molécula. Taskin e Bernholt (2014) concluíram que, na relação das equações químicas com os modelos, os estudantes não consideraram o balanceamento das equações químicas.

\section{Percepção dos estudantes sobre a função das representações visuais}

Além das questões que nos permitiram identificar algumas dificuldades, construímos duas questões que nos fornecesse elementos para compreendermos como os estudantes percebem a função das representações visuais na Química. Em uma das questões fomos diretos, perguntando sobre a utilidade das fórmulas e equações químicas. Na outra questão, apresentamos algumas equações que indicavam a formação de um fármaco a partir de um determinado reagente. Quando se modifica um grupo desse reagente, não ocorre formação do fármaco. Com base nisso, questionamos se as informações foram relevantes para avaliar se a produção do fármaco era possível ou não e que justificassem. A partir das respostas dos estudantes, duas categorias emergiram, conforme discutidas a seguir.

A percepção dos estudantes sobre a função das representações visuais está fortemente relacionada à comunicação de informações, pois para eles "as fórmulas e equações químicas utilizadas nos traz a possibilidade de conhecermos melhor os elementos químicos com os quais estamos em contato no dia a dia e nos previne do contato com produtos tóxicos e das reações que eles geram". Na questão que envolveu 
a produção do fármaco, isso também ficou evidenciado devido à associação do papel das representações visuais à comunicação de informações, pois o estudante afirma que "sim [assegurando que as representações visuais usadas para a produção do fármaco foram relevantes], pois mostra o composto que não pode ser usado, porque se for, o resultado dá errado". Os estudantes consideraram que a comunicação de informações por meio das representações visuais é importante para o aprendizado.

As representações visuais como forma de comunicar as experiências e os modelos têm sido defendidas por diversos pesquisadores, conforme já mencionados neste artigo, Mortimer (1996) e Talanquer (2011). No entanto, devemos explicitar para os nossos estudantes que essa comunicação facilitada pelas representações visuais (TALANQUER, 2011) não significa a comunicação da realidade (MORTIMER, 1996). Treagust e Chittleborough (2001) alertaram para o fato de que os estudantes muitas vezes transferem as propriedades macroscópicas de uma substância para suas partículas submicroscópicas, acreditando, por exemplo, que o enxofre é amarelo, de modo que os átomos de enxofre são amarelos também. Se isso acontece nesse movimento das experiências para os modelos, muito provavelmente, pode ocorrer no movimento entre modelos e representações visuais e/ou experiências e representações visuais.

Muitos estudantes consideraram o papel das representações visuais como uma formalização exigida para quem estuda ou trabalha na área da Química, pois "apenas percebo utilidade pois [sic] sou estudante do curso técnico em química, caso contrário, não veria nenhum uso prático das fórmulas e equações químicas estudadas". Os estudantes perceberam que as representações visuais não desempenham função alguma na Química, mas apenas para quem faz curso de Química. Eles ainda afirmaram que as representações visuais "são desenhos sem significado e que não fazem parte do cotidiano". Essa consideração feita pelo estudante leva-nos a uma das afirmações de Taskin e Bernholt (2014) de que os estudantes ficam balanceando equações por várias aulas sem entenderem os motivos para isso. O que nos indica que a representação visual é percebida como uma mera abordagem de objeto, concebendo essa representação como um produto que independe da atividade científica (EVAGOROU; ERDURAN; MÄNTYLÄ, 2015; PAUWELS, 2006). Dessa forma, os estudantes não perceberam as representações visuais como forma de comunicação do conhecimento químico e, muito menos, como necessárias para a construção desse conhecimento.

Muitas das dificuldades dos estudantes acerca das representações visuais, seja no entendimento ou no uso delas, podem se relacionar à percepção que eles possuem sobre a função dessas representações. Isso porque, se eles percebem-nas como apenas uma ilustração da Química, elas são memorizadas e aplicadas sem interpretação do contexto de aplicação, ou seja, entendidas como um produto que transmite seu conteúdo por si mesmo. Por exemplo, quando o estudante utiliza, inadequadamente, a representação $\mathrm{H}^{+}$para indicar a carga do metilamônio (figura 2). Essa representação é utilizada para indicar a transferência de um átomo de hidrogênio sem o elétron, caracterizando a acidez de um composto. O estudante ainda explicita a função dessa representação para caracterizar a natureza ácida do composto. Por mais que essa representação seja adequada para indicar a natureza ácida em uma ligação com o nitrogênio, para indicar a carga do metilamônio ela não se sustenta. No caso do metilamônio, a carga positiva está relacionada ao átomo de nitrogênio, e não, ao átomo de hidrogênio. Assim, a representação $\mathrm{H}^{+}$não é adequada para qualquer 
situação. Perini (2005b) afirma que os sistemas de símbolos consistem em caracteres que podem ser classes de enunciados ou marcas visíveis e regras que atribuem referentes a caracteres. A compreensão desses sistemas de símbolos requer interpretação, pois nenhum objeto transmite conteúdo apenas em virtude de suas próprias propriedades. Dessa forma, todo sistema de símbolos é governado por 'regras' interpretativas que são, pelo menos, parcialmente convencionais.

\section{Considerações e implicações}

Nesse trabalho, identificamos as dificuldades dos estudantes do Ensino Médio com as representações visuais usadas na Química e compreendemos a percepção que eles possuem sobre a função delas. Com relação à nossa questão de pesquisa, indicamos que as dificuldades que os estudantes possuem para lidar com as representações visuais relacionam-se à forma como a função delas é percebida por eles. Ao considerarem que elas servem como uma ilustração da Química, os estudantes utilizam-nas como um produto, o que colabora com as dificuldades de compreensão, construção e relação com os outros tipos de conhecimento químico necessários para o processo de ensino e aprendizagem. Não é nosso intuito considerar o conhecimento químico como dissociável, mas entender o que conta como conhecimento necessário para aulas de Química, ou seja, quais alegações de conhecimento são importantes para a compreensão dos fenômenos e processos químicos.

Nesse sentido, o ensino dessas representações visuais, desvinculado dos outros tipos de conhecimento químico (TALANQUER, 2011) e como um produto, pode contribuir para o entendimento das dificuldades apresentadas pelos estudantes. Quadros, Silva e Mortimer (2018) discutem sobre a importância de o professor ser capaz de demonstrar que um determinado conceito pode ser trabalhado nesses diferentes tipos de conhecimento (TALANQUER, 2011), mas que, além disso, o professor seja capaz de demonstrar para os estudantes que esses tipos estão interligados em uma única explicação. Assim, conforme defende Talanquer (2018), o entendimento de um fenômeno envolve também a produção de justificativas, argumentos e explicações. Dessa forma, não se entende um fenômeno demonstrando cada tipo de conhecimento químico, mas nos movimentos que são feitos no uso deles para o entendimento desse fenômeno; daí, portanto, a necessidade de que as representações não sejam ensinadas de forma isolada e desvinculadas do seu contexto de produção.

As representações visuais usadas na Química, aqui pensando no campo da ciência, não se dão para formalizar esse campo de conhecimento, mas para produzir o próprio conhecimento químico. A síntese de um composto não se dá diretamente em um laboratório e, em seguida, uma equação química é construída para formalizar a produção desse composto. O composto é concebido inicialmente a partir das equações químicas propostas, indicando a viabilidade, ou não, de se produzir esse composto para, posteriormente, ser sintetizado no laboratório. Caso ocorra a formação de um produto inesperado, as regras interpretativas e convencionalizadas nesse sistema de símbolos podem ser mobilizadas para justificar a formação desse produto. A partir desse exemplo, de forma bem simplificada, podemos perceber que as representações visuais são necessárias na produção do conhecimento químico. 
Reconhecemos que essa discussão de que as representações visuais são necessárias para a construção do conhecimento químico não é nova na área, mas buscamos ressignificar essa discussão, mostrando que as dificuldades dos estudantes se relacionam com a percepção que eles possuem sobre a função dessas representações.

Como implicações desse estudo para o ensino, apoiados nas ideias de Perini (2002, 2004, 2005a, 2005b), sugerimos que as dificuldades dos estudantes podem ser minimizadas a partir de uma mudança da percepção que os estudantes possuem sobre a função das representações visuais. Na perspectiva de que elas não servem apenas para representar ou comunicar o conhecimento químico, mas são necessárias para a construção e desenvolvimento desse conhecimento, apoiando hipóteses, produzindo justificativas, fundamentando os argumentos, elaborando as explicações e expressando conclusões. Isso implica numa transformação da abordagem dessas representações nas aulas de Química, envolvendo-as em atividades interativas e críticas que engajam os estudantes na construção do conhecimento químico. Em outras palavras, não basta informar o que elas significam e como devem ser usadas, mas trazê-las a partir do seu contexto de produção e envolvidas nos processos dialógicos desencadeados durante essas atividades. Para a pesquisa, considerando essa abordagem acerca das representações visuais, estendemos a possibilidade de ampliação desse estudo para a análise das imagens muito frequentes em aplicativos e simulações, que se fazem muito presentes no contexto do ensino de Química.

\section{Agradecimentos}

O primeiro autor desse artigo agradece ao financiamento concedido pela Pró-Reitoria de Pesquisa da Universidade Federal de Minas Gerais (Edital 11/2017, Programa de Auxílio a Doutores Recém-Contratados).

\section{Referências}

ARAÚJO-NETO, W. N. Formas de uso da noção de representação estrutural no ensino superior de química. 2009235 f. Tese (Doutorado em Química) - Universidade de São Paulo, São Paulo, 2009.

BEEK, K. V.; LOUTERS, L. Chemical language skills: investigating the deficit. Journal of Chemical Education, Washington, v. 68, n. 5, p. 389-392, 1991. DOl: https://doi.org/df7xqp.

EVAGOROU, M.; ERDURAN, S.; MÄNTYLÄ, T. The role of visual representations in scientific practices: from conceptual understanding and knowledge generation to 'seeing' how science works. International Journal of STEM Education, Heidelberg, v. 2, n. 1, p. 11-24, 2015. DOI: https:// doi.org/ghmpf4.

FERREIRA, C. R.; ARROIO, A. Visualizações no ensino de química: concepções de professores em formação inicial. Química Nova na Escola, São Paulo, v. 35, n. 3, p. 199-208, 2013. Disponível em: https://cutt.ly/fETJENm. Acesso em: 28 set. 2021.

FERREIRA, M.; DEL PINO, J. C. Estratégias para o ensino de química orgânica no nível médio: uma proposta curricular. Acta Scientiae, Canoas, v. 11, n.1, p. 101-118, 2009. Disponível em: https:// cutt.ly/PETJJt3. Acesso em: 28 set. 2021.

GILBERT, J. K.; JUSTI, R. Modelling-based teaching in science education. Dordrecht: Springer, 2016. 
GIORDAN, M.; SILVA-NETO, A. B.; AIZAWA, A. Relações entre gestos e operações epistêmicas mediadas pela representação estrutural em aulas de química e suas implicações para a produção de significados. Química Nova na Escola, São Paulo, v. 37, n. 1, p. 82-94, 2015. DOI: https://doi.org/ gxns.

GOIS, J.; GIORDAN, M. Semiótica na química: a teoria dos signos de Peirce para compreender a representação. Química Nova na Escola, São Paulo, n. 7, p. 34-42, 2007. Cadernos temáticos. Disponível em: https://cutt.ly/eETKoyU. Acesso em: 28 set. 2021.

GOODWIN, W. Visual representations in science. Philosophy of Science, Chicago, v. 76, n. 3, p. 372$390,2009$.

HAN, J-Y.; ROTH, W.-M. Chemical inscriptions in Korean textbooks: semiotics of macro and microworld. Science Education, Hoboken, v. 90, n. 2, p. 173-201, 2006. DOI: https://doi.org/ bx7mqd.

JACOB, C. Interdependent operations in chemical language and practice. HYLE: International Journal for Philosophy of Chemistry, Exeter, v. 7, n. 1, p. 31-50, 2001. Disponível em: https://cutt. ly/hETLJxl. Acesso em: 28 set. 2021.

JOHNSTONE, A. H. The development of chemistry teaching: a changing response to changing demand. Journal of Chemical Education, Washington, v. 70, n. 9, p. 701, 1993. DOI: https://doi.org/ c3xh5b.

MINAS GERAIS. Secretaria Estadual de Educação. Conteúdo básico comum: química. Belo Horizonte: SEE-MG, 2007.

MORAES, R.; GALIAZZI, M. C. Análise textual discursiva. 3. ed. Ijuí: Editora Unijuí, 2016.

MORTIMER, E. F. O significado das fórmulas químicas. Química Nova na Escola, São Paulo, n. 3, p. 19-21, 1996.

PAUWELS, L. A theoretical framework for assessing visual representational practices in knowledge building and science communications. In: PAUWELS, L. Visual cultures of science: rethinking representational practices in knowledge building and science communication. Lebanon, NH: Darthmouth College Press, 2006. p. 1-25.

PERINI, L. T. Visual representations and scientific knowledge. 2002. PhD Dissertation (Doctor in Philosophy) - University of California, San Diego, 2002.

PERINI, L. Convention, resemblance and isomorphism: understanding scientific visual representations. In: MALCOLM, G. (ed.). Studies in multidisciplinarity. Dordrecht: Elsevier, 2004. v. 2 , p. 37-47.

PERINI, L. The truth in pictures. Philosophy of Science, Chicago, v. 72, n. 1, p. 262-285, 2005a.

PERINI, L. Visual representations and confirmation. Philosophy of Science, Chicago, v. 72, n. 5, p. 913-926, 2005b.

POZZER-ARDENGHI, L.; ROTH, W-M. Toward a social practice perspective on the work of reading inscriptions in science texts. Reading Psychology, London, v. 31, n. 3, p. 228-253, 2010. DOI: https://doi.org/cgvcgz.

QUADROS, A. L.; SILVA, A. S. F.; MORTIMER, E. F. Relações pedagógicas em aulas de ciências da educação superior. Química Nova, São Paulo, v. 41, n. 2, p. 227-235, 2018. DOI: https://doi.org/ gxnw.

ROQUE, N. F.; SILVA, J. L. P. B. A linguagem química e o ensino da química orgânica. Química Nova, São Paulo, v. 31, n. 4, p. 921-923, 2008. DOl: https://doi.org/chj4zd. 
SILVA, E. P. C.; SILVA, F. C. Nível simbólico da química orgânica no ensino médio: construção de instrumento de produção de dados para identificação das principais dificuldades dos estudantes. In: SEMANA DE INICIAÇÃO CIENTÍFICA DA PRÓ-REITORIA DE PESQUISA DA UFMG, 27., 2018. Belo Horizonte: PRPq-UFMG, 2018.

SOUZA, K. A. F. D. Estratégias de comunicação em química como índices epistemológicos: análise semiótica das ilustrações presentes em livros didáticos ao longo do século XX. 2012. 189 f. Tese (Doutorado em Química) - Universidade de São Paulo, São Paulo, 2012. DOI: https://doi.org/ gznq.

TABER, K. S. Learning at the symbolic level. In: GILBERT, J. K.; TREAGUST, D. F. (ed.). Multiple representations in chemical education. Perth: Springer, 2009. p. 75-105.

TALANQUER, V. Macro, submicro, and symbolic: the many faces of the chemistry 'triplet'. International Journal of Science Education, Philadelphia, v. 33, n. 2, p. 179-195, 2011. DOI: https:// doi.org/dsnfbf.

TALANQUER, V. Chemical rationales: another triplet for chemical thinking. International Journal of Science Education, Philadelphia, v. 40, n. 15, p. 1874-1890, 2018.

TASKIN, V.; BERNHOLT, S. Students' understanding of chemical formulae: a review of empirical research. International Journal of Science Education, Philadelphia, v. 36, n. 1, p. 157-185, 2014.

TEIXEIRA, P. M. M.; MEGID-NETO, J. Uma proposta de tipologia para pesquisas de natureza interventiva. Ciência \& Educação, Bauru, v. 23, n. 4, p. 1055-1076, 2017. DOI: https://doi.org/gxnx.

TERUYA, L. C.; MARSON, G. A.; FERREIRA, C. R.; ARROIO, A. Visualização no ensino de química: apontamentos para a pesquisa e desenvolvimento de recursos educacionais. Química Nova, São Paulo, v. 36, n. 4, p. 561-569, 2013.

TREAGUST, D. F.; CHITTLEBOROUGH, G. Chemistry: a matter of understanding representations. In: BROPHY, J. (ed.). Subject-specific instructional methods and activities. Bingley: Emerald, 2001. p. 239-267.

VLADUŠIĆ, R.; BUCAT, R.; OŽıĆ, M. Understanding of words and symbols by chemistry university students in Croatia. Chemistry Education Research and Practice, London, v. 17, n. 3, p. 474-488, 2016. DOI: https://doi.org/gxnz.

WARTHA, E. J.; REZENDE, D. B. A elaboração conceitual em química orgânica na perspectiva da semiótica peirceana. Ciência \& Educação, Bauru, v. 21, n. 1, p. 49-64, 2015. DOI: https://doi.org/ gxn2. 